\title{
In vitro haemostatic effect of amphibian crude skin secretions in rabbit blood plasma
}

\author{
Iryna Udovychenko, ${ }^{1}$ Yuliia Dudkina, ${ }^{1}$ Denys Oliinyk, ${ }^{1}$ Oleksandra Oskyrko, ${ }^{2}$ Oleksii Marushchak, ${ }^{3}$ \\ Tetiana Halenova, ${ }^{1}$ Olexii Savchuk ${ }^{1}$ \\ ${ }^{1}$ Department of Biochemistry, Educational and Scientific Centre - Institute of Biology and Medicine, Taras Shevchenko \\ National University of Kyiv; ${ }^{2}$ Department of Zoology, Educational and Scientific Centre - Institute of Biology and \\ Medicine, Taras Shevchenko National University of Kyiv; ${ }^{3}$ I. I. Schmalhausen Institute of Zoology, National Academy \\ of Sciences of Ukraine, Kyiv, Ukraine
}

\begin{abstract}
In this research we have studied whether the amphibian crude skin secretions can modify some parameters of haemostatic system. We prepared the samples of crude skin secretions of Bombina bombina, Bombina variegata, Bufo bufo, and Bufotes viridis and investigated the plasma clotting function in vitro by performing activated partial thromboplastin time (aPTT), prothrombin time and thrombin time (TT) assays. The data indicate that the components of B. bombina and B. variegata skin secretions significantly prolonged aPTT clotting time, while the components of $B$. viridis skin secretions prolonged the time of plug formation in TT. The proteolytic activity and the ability of the skin secretions components to activate plasma proenzymes were
\end{abstract}

Correspondence: Iryna Udovychenko, Department of Biochemistry, Educational and Scientific Centre - Institute of Biology and Medicine, Taras Shevchenko National University of Kyiv, Volodymyrska Str. 64/13, 01601, Kyiv, Ukraine.

Tel. +380683407357 .

E-mail: iryna.udovychenko168@gmail.com

Key words: Amphibian skin secretions; Plasma coagulation tests; Proteolytic activity; Plasma proenzymes; Platelet aggregation.

Contributions: the authors contributed equally.

Conflict of interest: the authors declare no potential conflict of interest.

Funding: this research was supported by the Ministry of Education and Science, Ukraine [n. 0116U002527, 2016-2018].

Received for publication: 7 August 2019

Revision received: 24 September 2019.

Accepted for publication: 2 October 2019.

${ }^{\circ}$ Copyright: the Author(s), 2019

Licensee PAGEPress, Italy

Journal of Biological Research 2019; 92:8475

doi:10.4081/jbr.2019.8475

This article is distributed under the terms of the Creative Commons Attribution Noncommercial License (by-nc 4.0) which permits any noncommercial use, distribution, and reproduction in any medium, provided the original author(s) and source are credited. assayed in vitro using synthetic chromogenic substrates. The components of $B$. variegata skin secretions cleaved all studied chromogenic substrates, whereas the $B$. viridis secretions intensively cleaved thrombin specific substrate and protein $\mathrm{C}$ specific substrate. The components of $B$. bombina and B. bufo skin secretions activated prothrombin and protein $C$ in plasma. The components of $B$. variegata, $B$. bufo and $B$. viridis skin secretions in a dosedependent manner induced platelet aggregation.

\section{Introduction}

Over the past several decades, a great deal of emphasis has been placed on the search for the new natural sources of biologically active compounds for the development of novel pharmacologically effective agents. ${ }^{1,2}$ Considering the wide distribution of the amphibians throughout the mainland of Europe and the variety of the already recognized activities of the biologically active compounds derived from their dermal venoms, amphibian skin secretions seems to be a perfect raw material to search for the novel promising bioactive compounds and/or new effects of the already known constituents. ${ }^{3,4}$

Since ancient times, amphibian venoms have always considered to be highly efficient in fighting different diseases. ${ }^{5}$ Extensive studies have been conducted to study the therapeutic potential of the components of skin secretions of various types of amphibians. ${ }^{6-8}$ The experimental data show that the amphibian glandular secretions are a rich source of various molecules with cardiotonic, ${ }^{9}$ antidiabetic, ${ }^{10}$ immunomodulatory, ${ }^{11}$ antimicrobial, ${ }^{12,13}$ and antiviral activities. ${ }^{14,15}$ A great number of researches also state that they have sedative and analgesic effects. ${ }^{16,17}$

It is generally agreed that the haemostasis system disorders are a major cause of morbidity and mortality. ${ }^{18}$ Despite the wide arsenal of medicines, the prevalence rate is constantly increased. In recent years, the search for new pharmacological approaches to the prevention and treatment of these conditions is underway, although, the ideal drug has not yet been found. The bioactive components derived from the reptile venoms are actively used in the treatment of various haemostasis disorders. ${ }^{19}$ Furthermore, some similar studies regarding the effects of a poisonous species of amphibians were conducted in Asian countries. ${ }^{20}$ However, little research has been undertaken to study the effects of the crude skin secretions constituents of the amphibian species that dwell Eastern Europe on some parameters of the haemostasis system.

In the present study, the amphibian crude skin secretions were 
investigated for its haemostatic effect by determining the plasma clotting time and platelet aggregation. Also the proteolytic activity and the ability of the skin secretions components to activate plasma proenzymes were assayed. The components of all studied amphibian secretions had effects on different parameters. Currently the fractionation and the purification of an active component from the fractions and further molecular characterization of specific target proteins are in course.

\section{Materials and Methods}

\section{Collection of amphibian skin secretions}

All animal procedures followed the European Directive 2010/63/EU (EC, 2010) on protecting animals used for experimental and other scientific purposes. All manipulations were approved by the Ethical Committee of Educational and Scientific Centre Institute of Biology and Medicine, Taras Shevchenko National University of Kyiv, Ukraine.

Adult specimens (both sexes) of Bombina bombina $(n=20)$, Bombina variegata $(n=20)$, Bufo bufo $(n=15)$, and Bufotes viridis $(n=10)$ were collected outdoors on the territory of Ukraine and were authenticated by the Department of Zoology and Ecology of Taras Shevchenko National University of Kyiv, Ukraine. Amphibians were kept in fauna boxes of different volumes and were fed 2-3 times a week with a frozen food on the basis of representatives of Orthoptera and Blattoptera, and larvae of Diptera. Water in the fauna boxes was changed once a week.

Skin secretions were collected as follows: frogs were put into a petri dish. Being mechanically stimulated with fingers for 1-2 min, frog skin surface was seen to exude copious secretions. Skin secretions were collected by washing the dorsal region of each frog with ultra-pure water. Water suspensions of skin secretions were centrifuged at 2,500 $\mathrm{g}$ for $15 \mathrm{~min}$ to remove debris. The supernatants were lyophilized (Telstar LyoQuest) and kept at $4{ }^{\circ} \mathrm{C}$ till use.

\section{Samples preparation}

The samples of lyophilized skin secretions $(30 \mathrm{mg}$ of dried material) were resuspended in $1 \mathrm{~mL} 0.05 \mathrm{M}$ Tris- $\mathrm{HCl}$ buffer, $\mathrm{pH} 7.4$, which contained $0.13 \mathrm{M} \mathrm{NaCl}$ and centrifuged at 7,000 g for $15 \mathrm{~min}$. Protein concentration in the supernatant was assayed by Bradford (1976) method, ${ }^{21}$ using bovine serum albumin as a standard.

\section{Preparation of platelet-rich plasma and platelet-pure plasma}

Healthy adult rabbits were supplied by the vivarium of Taras Shevchenko National University of Kyiv, Ukraine. All animal experiments were approved by the Animal Care Committee of Taras Shevchenko National University of Kyiv, Ukraine. Plateletrich plasma (PRP) and platelet-pure plasma were obtained following the standard protocol. ${ }^{22}$ All procedures were carried out at room temperature. Rabbit blood was collected from the ear artery into a polyethylene tube with $3.8 \%$ sodium citrate in the ratio 9:1. PRP was obtained by centrifugation of stabilized blood at $300 \mathrm{~g}$ for 10 min. The supernatant (PRP) was carefully separated and used further in the aggregation assay. Platelet-pure plasma was prepared by further centrifugation of the remained stabilized blood at $1,500 \mathrm{~g}$ for $30 \mathrm{~min}$.

\section{Plasma coagulation tests}

Activated partial thromboplastin time (aPTT), thrombin time (TT) and prothrombin time (PT) were measured in vitro to assess the effects of the components of amphibian skin secretions on plasma clotting function. The tests were conducted using the coagulation analyser (Rayto RT-2201C, China) and the standard set of reagents (RENAM, Russian Federation). Briefly, to check the clot forming in aPTT test, $45 \mu \mathrm{L}$ of plasma was mixed with $5 \mu \mathrm{L}$ of the skin secretions sample and $50 \mu \mathrm{L}$ of aPTT reagent in the coagulometric cuvette and incubated for $3 \mathrm{~min}$ at $37^{\circ} \mathrm{C}$. Clotting time in seconds (s) was recorded after the addition of $50 \mu \mathrm{L}$ of $0.025 \mathrm{M} \mathrm{CaCl}$. For TT assay $45 \mu \mathrm{L}$ of plasma and $5 \mu \mathrm{L}$ of the skin secretions sample was mixed with $100 \mu \mathrm{L}$ of thrombin (final activity $3 \mathrm{U} / \mathrm{mL}$ ) in the coagulometric cuvette and time necessary for clotting plug formation was recorded. The time in PT test was assessed by mixing $45 \mu \mathrm{L}$ of plasma and $5 \mu \mathrm{L}$ of skin secretions sample with $100 \mu \mathrm{L}$ of thromboplastin-Calcium mixture. All coagulation assays were performed in triplicate using plasma from three different rabbits. Plasma incubated with other components and equal amounts of ultra-pure water, instead of skin secretions samples, was used as controls.

\section{Chromogenic assays}

The effects of crude skin secretions of studied amphibian species on key haemostasis enzymes were assayed using chromogenic substrates with detectable leaving groups: thrombin specific substrate Phe-Pip-Arg-pNA (S 2238), plasmin specific substrate Val-Leu-Lys-pNA (S 2251), factor Xa specific substrate IleGlu-Gly-Arg-pNA (S 2222) and activated protein C specific substrate pyroGlu-Pro-Arg-pNA (S 2366) (RENAM, Russian Federation).

To determine the proteolytic activity of the components of crude skin secretions of B. bombina, B. variegata, B. bufo and $B$. viridis, in vitro experiments were performed. The incubation medium with a final volume of $250 \mu \mathrm{L}$ contains: $0.05 \mathrm{M}$ Tris$\mathrm{HCl}$ buffer, $\mathrm{pH} 7.4$ and a sample of skin secretions containing $20 \mu \mathrm{g}$ of the total protein. After $5 \mathrm{~min}$ of incubation at $37^{\circ} \mathrm{C}$ in a 96-well plate, the reaction was initiated by adding corresponding specific chromogenic substrate (in a final concentration of $0.3 \mathrm{mM}$ ). The control sample contained the same components but with an equal volume of $0.05 \mathrm{M}$ Tris-HCl, $\mathrm{pH} 7.4$ instead of the sample of amphibian skin secretions. Incubation was performed at $37^{\circ} \mathrm{C}$ for 2 hours. The intensity of the proteolytic activity was proportional to the colour that revealed in the result of the gradual release of $p$-nitroaniline from the chromogenic substrate. The amount of $p$-nitroaniline hydrolyzed from the substrate was recorded at equal intervals of time (every $15 \mathrm{~min}$ for $120 \mathrm{~min}$ ) at $405 \mathrm{~nm}$ using the kinetic microplate spectrophotometer ( $\mu$ Quant, BioTek).

To study the ability of the components of crude skin secretions of $B$. bombina, $B$. variegata, $B$. bufo and $B$. viridis to activate plasma proenzymes in vitro experiments were carried out. Incubation medium $(250 \mu \mathrm{L})$ of the similar composition was used: $0.05 \mathrm{M}$ Tris- $\mathrm{HCl}$ buffer, $\mathrm{pH} 7.4$ and the samples of skin secretions $(20 \mu \mathrm{g}$ of total protein) were mixed with $20 \mu \mathrm{L}$ of plasma for $5 \mathrm{~min}$ at $37^{\circ} \mathrm{C}$ and then the corresponding specific chromogenic substrate (in a final concentration of $0.3 \mathrm{mM}$ ) was added. Incubation was performed at $37^{\circ} \mathrm{C}$ for 2 hours. The intensity of $p$-nitroaniline release was measured at the equal intervals of time (every $15 \mathrm{~min}$ ). The control sample contained the same components but with an equal volume of $0.05 \mathrm{M}$ Tris-HCl, $\mathrm{pH} 7.4$ instead of amphibian skin secretions. During the computation of the results, the optical density of plasma was subtracted from the optical density of plas- 
ma that was incubated with the samples of skin secretion. Then the values of the optical density of the previous experiment were also subtracted to show the effect of crude skin secretions on plasma proenzymes.

\section{Platelet aggregation assays}

Platelet aggregation assay was undertaken within the first $3 \mathrm{~h}$ after blood sampling using photo-optical aggregometer AT-02 (Medtech, Russia). Before the assessment, the number of platelets in PRP was determined $\left(230-250 \times 10^{3}\right.$ cells $\left./ \mu \mathrm{L}\right)$. The effects of the components of the skin secretions on platelet functions were performed in vitro. Briefly, $380 \mu \mathrm{L}$ PRP and $20 \mu \mathrm{L}$ of the samples with $50 \mu \mathrm{g}$ of total protein were incubated at $37^{\circ} \mathrm{C}$ in the aggregometer cuvette and the aggregation process was monitored for $5 \mathrm{~min}$. The maximum degree of aggregation was recorded and compared with the degree of aggregation in response to one of the platelet physiological inducers - ADP (Sigma, USA) in the final concentration $5 \times 10^{-6} \mathrm{M}$.

When the direct effect of the skin secretions samples on platelet aggregation was observed the concentration dependence study was carried out. Thus in the same experiment we have studied the effects

Table 1. The clotting time (sec) of the rabbit blood plasma in the coagulation tests after incubation with the amphibian skin secretions.

\begin{tabular}{lccc} 
& aPTT & PT & TT \\
Control & $18.6 \pm 2.6$ & $7 \pm 0.1$ & $28.2 \pm 4.3$ \\
B. bombina & $62.7 \pm 14.3^{*}$ & $7.1 \pm 0.2$ & $29.1 \pm 1.3$ \\
\hline B. variegata & $41.9 \pm 15.2^{*}$ & $6.9 \pm 0.1$ & $29.1 \pm 0.7$ \\
B. bufo & $20.8 \pm 3.1$ & $6.8 \pm 0.5$ & $30.9 \pm 1.6$ \\
\hline B. viridis & $21.0 \pm 0.8$ & $7.2 \pm 0.2$ & $39.1 \pm 1.6^{*}$
\end{tabular}

aPTT, activated partial thromboplastin time; PT, prothrombin time; TT, thrombin time. *P $\leq 0.05$, the difference is comparable to the control.
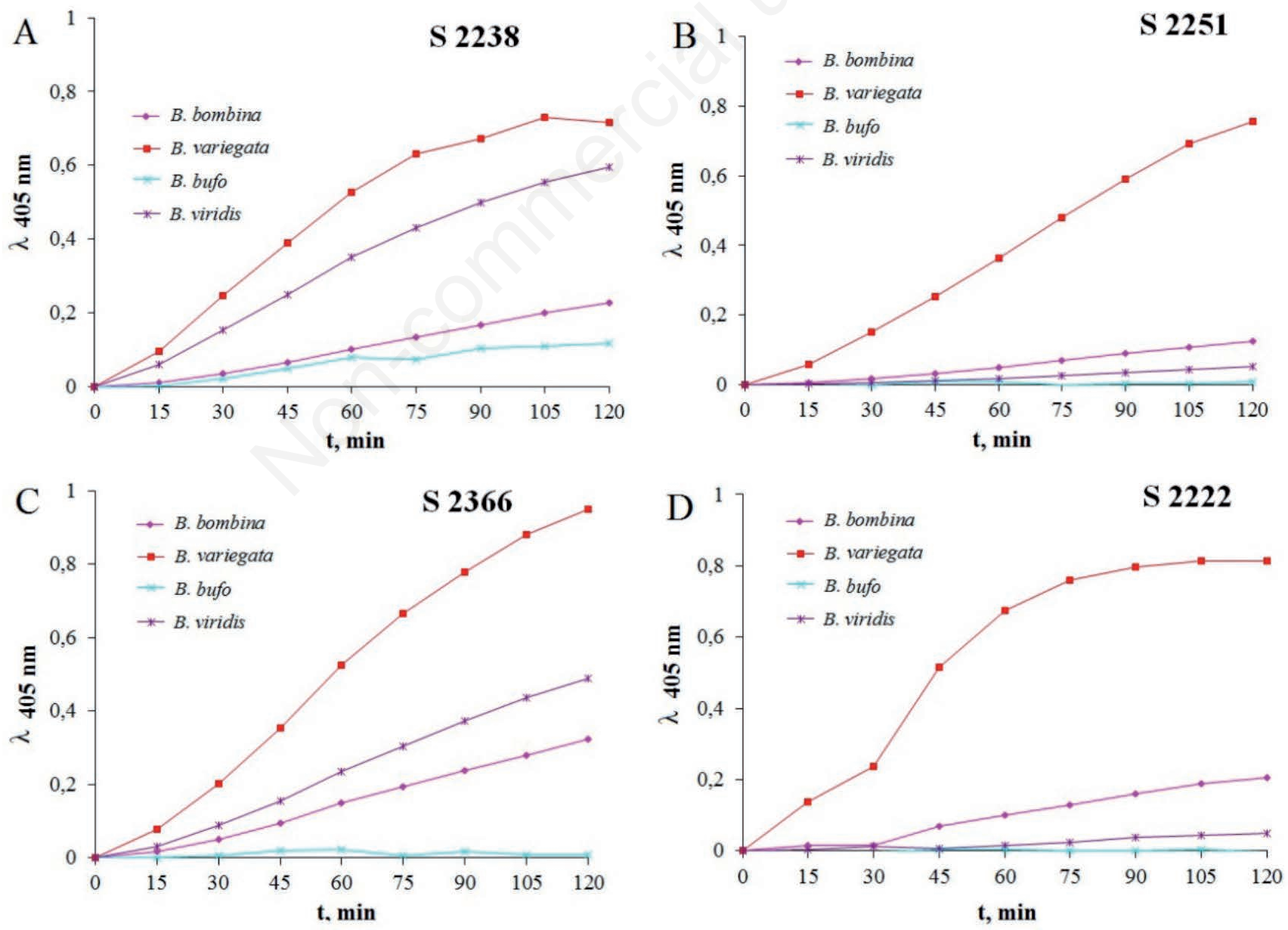

Figure 1. Proteolytic activity of the components of amphibian crude skin secretions to the thrombin specific substrate (A), plasmin specific substrate (B), protein C specific substrate (C) and factor Xa specific substrate (D). 
of amphibian skin secretions in the final concentrations of $250 \mu \mathrm{g}$, $125 \mu \mathrm{g}, 50 \mu \mathrm{g}$ and $25 \mu \mathrm{g}$ of total protein in $1 \mathrm{~mL}$ of PRP.

If the direct activation effect of the test sample on the process of platelet aggregation was not observed within the 3-min period, the ADP $\left(5 \times 10^{-6} \mathrm{M}\right)$ was added and the process of aggregation was monitored. The degree of ADP-dependent aggregation, after 3 minutes of incubation of PRP with Tris-buffered saline, $\mathrm{pH}=7.4$ (instead of studied samples), was used as a control for this experiment.

\section{Calculation of the results}

All experiments were performed in parallels and repeated at least three times each using the blood of different rabbits. The statistical analysis was performed using Stat Soft Statistica version 7.0 for Windows. The data were analysed for statistical significance of difference by Student's t-test. Differences were statistically significant when $\mathrm{P}<0.05$.

\section{Results}

\section{Activated partial thromboplastin time, prothrombin} time and thrombin time in vitro assays

The effects of amphibian crude skin secretions on the time of clotting plug formation, which corresponds the results of plasma coagulation tests (aPTT, TT and PT), are demonstrated in Table 1. The prolongation of aPTT by 3.4 times and 2.25 times was observed during the incubation of plasma with $B$. bombina and $B$. variegata crude skin secretions, respectively. The skin secretions of $B$. viridis prolonged TT clotting time to $39.1 \pm 1.6$ seconds vs $28.2 \pm 4.3$ in control. The PT assay showed none changes in the time of clotting plug formation during incubation of plasma with crude skin secretions of all studied species.

\section{Chromogenic assays}

As shown in Figure 1A, the components of B. variegata and $B$. viridis skin secretions intensively cleaved thrombin specific substrate $-\mathrm{S} 2238$. The $B$. variegata skin secretions also actively cleaved plasmin specific substrate - S 2251 (Figure 1B). Skin secretions of B. bombina and B. viridis showed mild proteolytic activity to activated protein $\mathrm{C}$ specific substrate $-\mathrm{S} 2366$, whereas the $B$. variegata skin secretions significantly cleaved this chromogenic substrate (Figure 1C). The incubation of factor Xa specific substrate - S 2222 with skin secretions of B. variegata also resulted in the progressive increase of the optical density of the samples (Figure 1D).

Figure 2 demonstrates the results of the ability of the components of B. bombina, B. variegata, B. bufo and B. viridis skin secretions to activate plasma proenzymes. To conduct this experiment rabbits' blood plasma was additionally added to the incubation
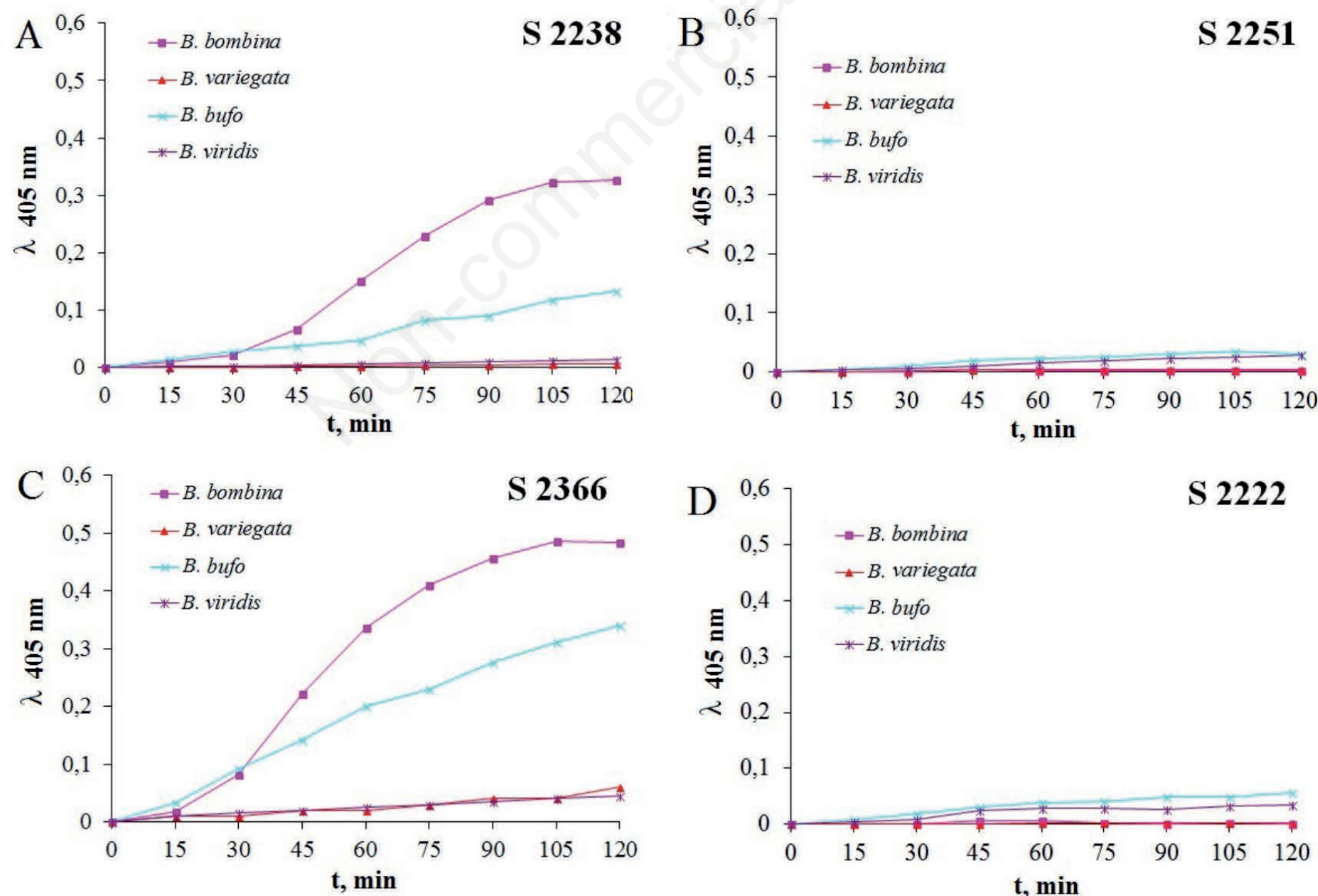

Figure 2. The ability of the components of the crude skin secretions of B. bombina, B. variegata, B. bufo and B. viridis to activate prothrombin, plasminogen, protein $\mathrm{C}$ and factor $\mathrm{X}$. 
medium with the appropriate substrate and samples of the amphibians' skin secretions. The optical density of plasma was subtracted from the values of the optical density of plasma, which was incubated with the samples of skin secretion. Then the results of the previous experiment were also subtracted. The intensive cleavage of the S 2238 and S 2366 substrates evidenced that the components of $B$. bombina and $B$. bufo crude skin secretions activate prothrombin and protein $\mathrm{C}$ in plasma (Figure $2 \mathrm{~A}$ and $\mathrm{B}$ ).

\section{Platelet aggregation in vitro assay}

The results of the potential effects of the crude skin secretions on the process of platelet aggregation are shown in Figure 3. The components of the $B$. bombina skin secretions had no effect on platelets and did not influence the ADP-dependent aggregation after $3 \mathrm{~min}$ of incubation with PRP (Figure $3 \mathrm{~A}$ ). The crude skin secretions of $B$. variegata, B. bufo, and $B$. viridis in a dose-depen- dent manner induced platelet aggregation in the rabbit PRP (Figure 3B-D). The degree of platelet aggregation under the influence of the three studied amphibian skin secretions, in the final concentration of $250 \mu \mathrm{g}$ of total protein in $1 \mathrm{~mL}$ of PRP, was identical to the values of the degree of aggregation in response to the action of $5 \times 10^{-6} \mathrm{M}$ ADP and was $60 \pm 3 \%$.

\section{Discussion}

The results of our study showed that the crude skin secretions of some amphibian species significantly prolonged the time of clotting plug formation in the aPTT and TT. The prolongation of these tests may be due to the presence of inhibitors of certain factors of coagulation haemostasis. On the other hand, this may be

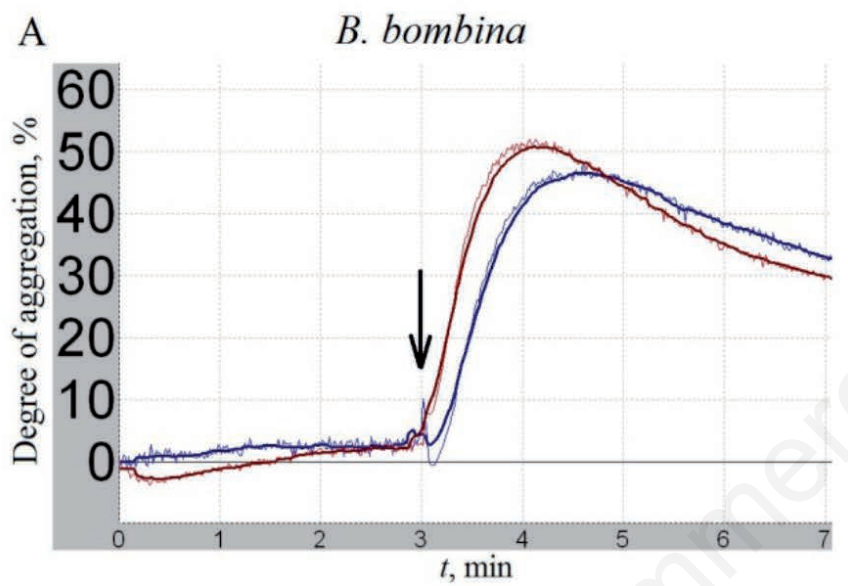

ADP $5 \times 10^{-6} \mathrm{M}$ crude skin secretions the time point when ADP was added

$$
\text { C }
$$
B. bufo

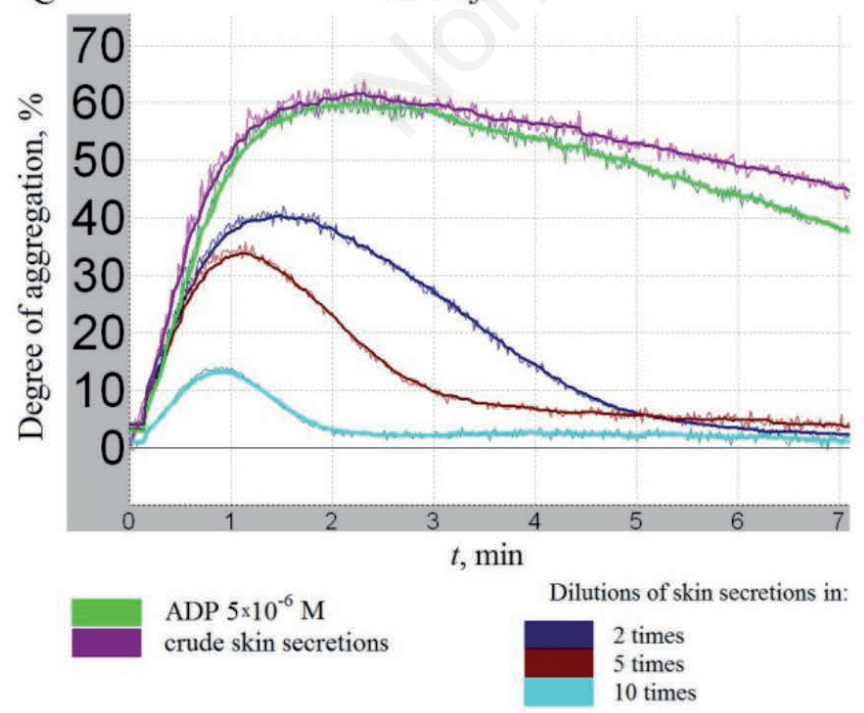

B

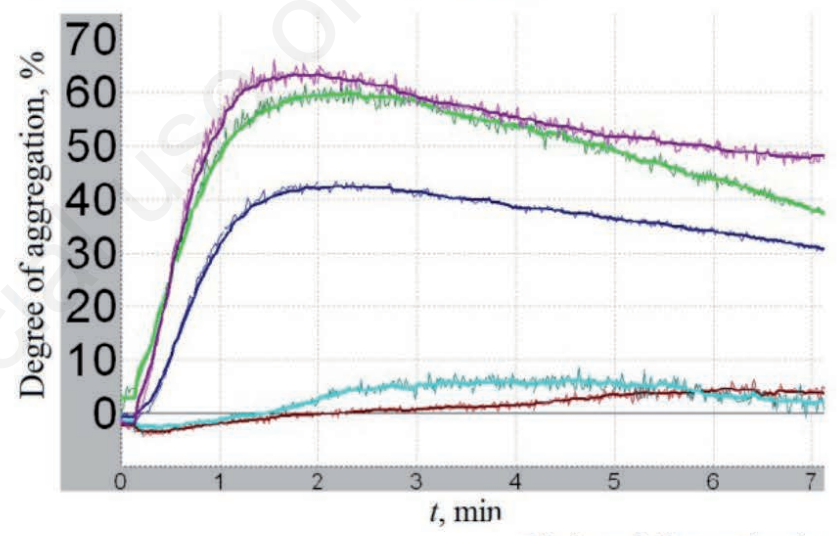

Dilutions of skin secretions in:

ADP $5 \times 10^{-6} \mathrm{M}$ crude skin secretions
D B. viridis

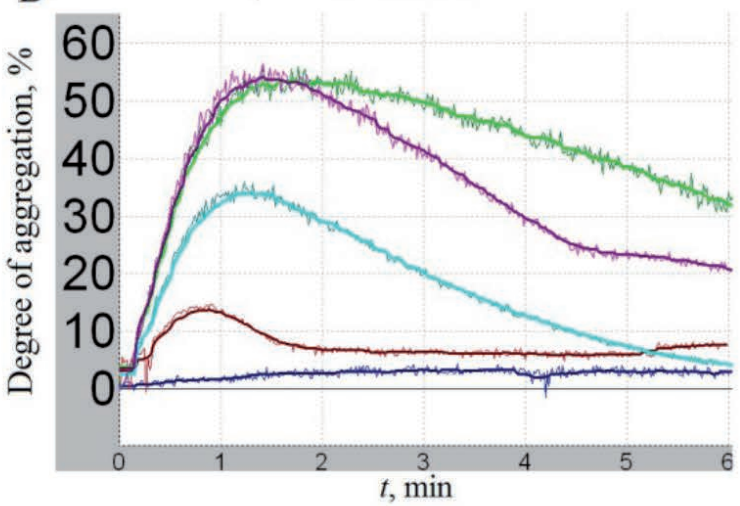

ADP $5 \times 10^{-6} \mathrm{M}$ crude skin secretions
Dilutions of skin secretions in: 2 times 5 times 10 times

Figure 3. The degree of platelet aggregation in rabbit platelet-rich plasma under the influence of skin secretions of studied amphibian species: B. bombina (A), B. variegata (B), B. bufo (C), and B. viridis (D). 
due to the degradation of the factors of coagulation haemostasis by active components of crude skin secretions. The last hypothesis corresponds to our previous results where we have stated that some crude skin secretions have a pronounced protease activity with specificity to different substrates. ${ }^{23}$

To further investigate the proteolytic activity of the studied amphibian crude skin secretions chromogenic assays were conducted. We used four synthetic chromogenic substrates - thrombin specific substrate, plasmin specific substrate, factor Xa specific substrate and activated protein $\mathrm{C}$ specific substrate. Unfortunately, currently we cannot make a precise conclusion on the fact that the components of $B$. variegata skin secretions cleaved all studied chromogenic substrates as it might be an action of a single enzyme, which has a wide substrate specificity, or the presence of several enzymes, each acting with very narrow specificity on one of the substrates. The corresponding researches should be made. The results of the effects of the $B$. viridis skin secretions during the incubation with studied chromogenic substrates were different: only two substrates were cleaved, that could be the evidence of the presence of the thrombin-like or protein C-like enzymes. B. bombina and B. bufo skin secretions had no significant changes in the optical density during the incubation with all studied chromogenic substrates. This represents the absence of active enzymes in their skin secretions that could affect the studied chromogenic substrates.

The next our experiment was to study the ability of the components of crude skin secretions to activate plasma proenzymes. It was revealed that the $B$. variegata and $B$. viridis skin secretions did not affect the activation of prothrombin, plasminogen, protein $\mathrm{C}$ and factor $\mathrm{X}$ in plasma. Such a conclusion was made as the substrates remained uncleaved after the incubation with the skin secretions. The intensive cleavage of thrombin specific substrate and protein $\mathrm{C}$ specific substrate indicated that the components of $B$. bombina and $B$. bufo skin secretions activate prothrombin and protein $C$ in plasma. There is some evidence to support our hypothesis stating that the appearance of thrombin and activated protein $\mathrm{C}$ may be due to the presence of an active forms of proteolytic enzymes in the skin secretions that directly activate the cleavage of the corresponding proenzymes or affect the cofactors that launch the cascade of the reactions and thus result in the formation of zymogens. We can assume two different ways of how the components of crude skin secretions can affect the thrombin molecules. The first can be carried out when the components of skin secretions directly affect the prothrombin molecules: initiate the cleavage of prothrombin and, therefore, stimulate the thrombin formation. The second is realized when the components can activate the factor $\mathrm{X}$ and affect the prothrombin activation.

In our in vitro study of platelet aggregation activity we demonstrated that the crude skin secretions of B. variegata, B. bufo and $B$. viridis in a dose-dependent manner induced platelet aggregation in the rabbit PRP. The components of these skin secretions could be the prominent source of inducers of platelet aggregation. Agents that can modulate platelets functioning are extremely relevant these days, as the available medications are characterized by a large number of side effects and unpredictable actions. Moreover, the search for inducers that can modulate platelets functions and their signalling pathways.

\section{Conclusions}

The results of our study demonstrate that the components of the studied amphibian crude skin secretions of B. bombina, B. var- iegata, B. bufo and B. viridis are a potential source of various active molecules that affect different stages of haemostasis system. However, the mechanism of their action and the nature of these compounds require additional researches. The continuation of the study of the amphibian skin secretions composition in this context may lay the foundations of the creation of novel biologically active substances with a direct therapeutic effect.

\section{References}

1. Gomes A, Giri B, Saha A, et al. Bioactive molecules from amphibian skin: Their biological activities with reference to therapeutic potentials for possible drug development. Indian. J Exp Biol 2007;45:579-93.

2. Dias D, Urban S, Roessner U. A historical overview of natural products in drug discovery. Metabolites 2012;2:303-36.

3. Conlon J, Leprince J. Identification and analysis of bioactive peptides in amphibian skin secretions. Methods Mol Biol 2010;615:145-57.

4. Bevins C, Zasloff M. Peptides from frog skin. Annu Rev Biochem 1990;59:395-414.

5. Lu AP, Jia HW, Xiao C, Lu QP. Theory of traditional Chinese medicine and therapeutic method of diseases. World $\mathrm{J}$ Gastroenterol 2004;10:1854-6.

6. Clarke BT. The natural history of amphibian skin secretions, their normal functioning and potential medicinal applications. Biol Rev 1997;72:365-79.

7. König E, Bininda-Emonds O, Shaw C. The diversity and evolution of anuran skin peptides. Peptides 1990;63:96-117.

8. Daly J. The chemistry of poisons in amphibian skin. Proc Natl Acad Sci 1995;92:9-13.

9. Morishita S, Shoji M, Oguni Y, et al. Congestive heart failure model in rabbits: effects of digoxin and a drug containing toad venom. Jpn J Pharmacol 1991;56:427-32.

10. Marenah L, Flatt PR, Orr DF, et al. Skin secretion of the toad Bombina variegata contains multiple insulin-releasing peptides including bombesin and entirely novel insulinotropic structures. Biol Chem 2004;385:315-21.

11. Shimizu Y, Inoue E, Ito C. Effect of the water-soluble and nondialyzable fraction isolated from Senso (Chan $\mathrm{Su}$ ) on lymphocyte proliferation and natural killer activity in $\mathrm{C} 3 \mathrm{H}$ mice. Biol Pharm Bull 2004;27:256-60.

12. Barberio C, Delfino G, Mastromei G. A low molecular weight protein with antimicrobial activity in the cutaneous 'venom' of the yellow-bellied toad (Bombina variegata pachypus). Toxicon 1987;25:899-909.

13. Soravia E, Martini G, Zasloff M. Antimicrobial properties of peptides from Xenopus granular gland secretions. FEBS Lett 1988;228:337-40.

14. Yasin B, Pang M, Turner JS. Evaluation of the inactivation of infectious Herpes simplex virus by host-defense peptides. Eur J Clin Microbiol Infect Dis 2000;19:187-94.

15. Chinchar VG, Wang J, Murti G, et al. Inactivation of frog virus 3 and channel catfish virus by esculentin-2P and ranatuerin-2P, two antimicrobial peptides isolated from frog skin. Virology 2001;288:351-7.

16. Montecucchi PC, Gozzini L, Erspamer V, Melchiorri P. The primary structure of tryptophan containing peptides from skin extracts of Phyllomedusa rhodei (tryptophyllins). Int J Peptide Res 1984;24:276-81.

17. Montecucchi PC, de Castiglione R, Piani S, et al. Amino acid 
composition and sequence of dermorphin, a novel opiate-like peptide from the skin of Phyllomedusa sauvagei. Int J Pept Protein Res 1981;17:275-83.

18. Mina A, Favaloro EJ, Koutts J. Hemostatic dysfunction associated with endocrine disorders as a major risk factor and cause of human morbidity and mortality: a comprehensive metareview. Semin Thromb Hemost 2007;33:798-809.

19. Karbovs'kyı̌ VL, Savchuk OM, Volkov HL, et al. Effect of proteins from the Agkistrodon blomhoffiiussuriensis snake venom on platelets in the hemostasis system. Ukr Biochem J 2007;79:82-89.

20. Zhang J, Zhang Y, Wan SG, et al. Bm-TFF2, a trefoil factor protein with platelet activation activity from frog Bombina maxima skin secretions. Biochem Biophys Res Commun 2005;330:1027-33.

21. Bradford MM. A rapid and sensitive method for quantities of utilizing the principle of protein binding. Anal Biochem 1976;7:248-54.

22. Pazzini J, De Nardi A, Huppes R, et al. Method to obtain platelet-rich plasma from rabbits (Oryctolagus cuniculus). Pesq Vet Bras 2016;36:39-44.

23. Nikolaieva I, Dudkina Yu, Oliinyk, D, et al. Amphibian skin secretions: a potential source of proteolytic enzymes. Biotechnol Acta 2018;11:42-8. 